\title{
Dietary intake of $B$ vitamins and methionine and breast cancer risk
}

Julie K. Bassett ${ }^{1}$, Laura Baglietto ${ }^{1,2}$, Allison M. Hodge ${ }^{1}$, Gianluca Severi ${ }^{1,2}$, John L. Hopper ${ }^{2}$, Dallas R.

English $^{1,2}$, Graham G. Giles ${ }^{1,2,3}$

${ }^{1}$ Cancer Epidemiology Centre, Cancer Council Victoria, 1 Rathdowne Street, Carlton South, Victoria 3053,

Australia

${ }^{2}$ Centre for Molecular, Environmental, Genetic and Analytic Epidemiology, School of Population and Global Health, University of Melbourne, 207 Bouverie Street, Carlton, Victoria 3053, Australia.

${ }^{3}$ Department of Epidemiology and Preventative Medicine, Monash University, Melbourne, Australia

Corresponding author:

Dr Julie Bassett

Cancer Epidemiology Centre

Cancer Council Victoria

1 Rathdowne Street, Carlton

Victoria 3053, AUSTRALIA

Phone: +6139635 5372, Fax: +6139635 5330

e-mail: julie.bassett@cancervic.org.au 


\section{Abstract}

Purpose: We investigated prospectively the relationship between dietary intakes of methionine and B vitamins associated with one-carbon metabolism and breast cancer risk, including modification by age, hormone receptor status and alcohol consumption. Interactions between different B vitamins and methionine were also examined.

Methods: During follow-up of 20,756 women from the Melbourne Collaborative Cohort Study for an average of 16 years, we ascertained 936 incident breast cancers. Dietary intakes were estimated using a 121-item food frequency questionnaire. Hazard ratios (HR) and 95\% confidence intervals were estimated using Cox regression. Results: We found weak evidence for an inverse association between breast cancer risk and riboflavin intake; (fourth versus first quartile, $\left.\mathrm{HR}_{\mathrm{Q} 4 \text { vs. Q1 }}=0.84(0.69,1.01) ; \mathrm{P}_{\text {linear trend }}=0.05\right)$ and a positive association for vitamin $\mathrm{B} 12\left(\mathrm{HR}_{\mathrm{Q} 4 \text { vs. } \mathrm{Q} 1}=1.21(1.00,1.46) ; \mathrm{P}_{\text {linear trend }}=0.06\right)$. We did not find any significant interactions between alcohol consumption and any of the $\mathrm{B}$ vitamins or methionine intake (all $\mathrm{P}_{\text {interaction }}>0.17$ ) or between methionine or folate intake and any other B vitamins (all $\mathrm{P}_{\text {interaction }}>0.07$ ). No association varied by tumour hormone receptor status (all $\left.\mathrm{P}_{\text {homogeneity }}>0.14\right)$.

Conclusions: We found weak evidence of an inverse association between breast cancer risk and riboflavin intake and a positive association with vitamin B12. 


\section{Introduction}

One-carbon metabolism comprises a complex network of biochemical pathways, involving interactions between several B vitamins, homocysteine and methionine. Folate and methionine are major sources of dietary methyl groups. Riboflavin, vitamin B6 and vitamin B12 are important cofactors in the one-carbon metabolism and might modulate the bioavailability of methyl groups. Disruption of one-carbon metabolism can interfere with DNA replication, DNA repair and regulation of gene expression through methylation, each of which could promote carcinogenesis[1]. Thus, dietary intake of B vitamins and methionine might play an important role in the development and progression of cancer.

Studies investigating associations between B vitamins and breast cancer risk have mainly focused on folate, vitamin B6 and B12. Two recent meta-analyses found no evidence from prospective studies for an association with dietary folate intake, whereas an inverse association was found for case-control studies[2,3]. However, heterogeneity among studies within each type of study design was noted [2], as was publication bias among case-control studies [3]. Most studies have generally reported null findings for overall breast cancer risk and vitamin B6[4-12], vitamin B12[4,7-11,13], riboflavin[14,15,8-10] and methionine[4,15,6,10,13].

Associations between B vitamin and methionine intake and breast cancer risk might be modified by other factors. It has been hypothesised that low folate intake might be associated with ER- breast tumours through its influence on methylation of the ER receptor, which could affect silencing of these genes [16] and some studies support this association [9,17]. Others have investigated modification by hormone receptor status with inconsistent findings $[18,6,19]$. High alcohol consumption is associated with increased breast cancer risk [20] and alcohol, a known folate-antagonist, can impair folate absorption and metabolism [21]. Adequate folate intake might attenuate the increased risk of breast cancer associated with alcohol consumption [2]. Other nutrients involved in the one-carbon metabolism might modify the association between folate and breast cancer, given the complex interactions involved, but findings have been inconsistent [2].

We investigated prospectively the relationship between dietary intakes of methionine and B vitamins associated with one-carbon metabolism and breast cancer risk, including modification by age, hormone receptor status and alcohol consumption. Interactions between different B vitamins and methionine were also examined. 


\section{Materials and Methods}

\section{The Cohort}

The Melbourne Collaborative Cohort Study (MCCS) is a prospective cohort study of 41,514 people $(24,469$ women) aged 27-80 at baseline[22]. The study protocol was approved by The Cancer Council Victoria's Human Research Ethics Committee. Follow-up has been conducted by record linkage to Electoral Rolls, electronic phone books, the Victorian Cancer Registry (VCR) and Victorian death records until 30 June 2010.

\section{Subjects}

We excluded women who had a diagnosis of breast cancer before study entry $(n=448)$, were missing data for any of the nutrients of interest $(n=11)$ and those who reported extreme values (top or bottom percentile) of total energy intake $(n=484)$. Women who reported a diagnosis of angina, heart attack or diabetes at baseline $(n=1402)$ were also excluded as they might have changed their diet due to their diagnosis. Ex-drinkers were also excluded as it was unknown how long these women had abstained from alcohol $(n=691)$. Those with missing values for any of the confounders $(n=676)$ and one woman who reported an unconfirmed cancer diagnosis 2 years after leaving Australia, were also excluded from the analyses. Altogether, data from 20,756 women including 936 incident cases were available for the analysis of total breast cancer. ER and PR status were unknown for 71 and 91 women respectively leaving 869 cases available for the ER/PR status analyses. There were no appreciable differences in baseline characteristics between women who had ER and PR status known and those who did not (all $\mathrm{P}>0.05)$.

\section{Identification of incident breast cancer cases}

Incident cases were identified from notifications of first diagnoses of breast cancer (International Classification of Diseases 10th revision rubric C50) to the VCR to 30 June 2010 and to the National Cancer Statistics Clearing House to 31 December 2004. Thus we were unable to follow-up women who moved outside of Victoria after 31 December 2004. Only subjects with invasive or metastatic primary cancers of the breast were counted as cases. We identified 936 incident breast cancer cases (average follow-up of 16.3 years).

\section{ER and PR status}


The medical records of women with breast cancer were reviewed and their cancers classified according to ER and PR status as recorded in histopathology reports held at the VCR. ER+ and PR+ tumours were identified as those with $\geq 1 \%$ staining or weak, moderate or strong intensity, and ER- and PR- tumours were identified as those with no staining. We repeated measurements of ER and PR status for a subset of cases with archival tissue available (77\% of all cases in the sample). Immunohistochemistry techniques used to determine ER and PR status have been described in detail elsewhere[23]. The agreements between ER and PR status assessed by immunohistochemistry and the values held by the VCR were $90 \%$ and $73 \%$, respectively (for ER, $\kappa=0.54$, $\mathrm{P}<0.0001$; for $\mathrm{PR}, \kappa=0.36, \mathrm{P}<0.0001)$. Given the good agreement between the ER and PR data, when archival tumour tissue was unavailable, ER and PR status was assigned according to the histopathology reports held at the VCR. For the hormonal receptor analyses, we had the following subtype combinations: 690 cases with ER+ or PR+ (ER+/PR+) and 179 cases with ER- and PR- (ER-\&PR-).

\section{Nutrient measures}

Participants completed a 121-item food frequency questionnaire (FFQ) specifically developed for the MCCS[24], and answered additional questions about alcohol intake. Sex-specific average portion sizes were assigned to each food item and daily frequencies of some fruits were seasonally adjusted. Nutrient composition data for the B vitamins and methionine were derived from the Australian NUTTAB 2006 database[25]. Mean daily intakes for the 5 nutrients (riboflavin (vitamin B2), vitamin B6, folate (vitamin B9), vitamin B12 and methionine) were obtained by multiplying the daily frequency of each food item by the nutrient composition for an average sex-specific portion size. Folate intake only included that occurring naturally in foods. Although, the FFQ has been validated for fatty acids [26] and carotenoids [27], it has not been validated specifically for B vitamins.

\section{Baseline data collection}

A structured interview was used to obtain information on reproductive history, hormone replacement therapy (HRT), oral contraceptive (OC) use, ethnicity, highest level of education, alcohol consumption, smoking status and physical activity (see reference[28] for further details). Height and weight were measured and BMI was calculated from these. 


\section{Statistical Analysis}

Follow-up began at study entry and continued until date of diagnosis of breast cancer or an unknown primary cancer, an unconfirmed breast cancer diagnosis, death, last known to be in Australia, last known to be in Victoria if after 2004 or 30 June 2010, whichever came first.

Intakes of energy and each nutrient were log transformed, and then nutrient intakes were adjusted for energy using the residuals method [29]. Quartile cut points (Q) for each energy-adjusted nutrient were obtained from the whole sample; the lowest quartile (Q1) being the referent category. To estimate linear trends on a log hazard scale, each nutrient variable was fitted as a pseudocontinuous covariate (using the median Q values). To investigate departures from linearity in the relationship between nutrient intake and breast cancer risk we included a quadratic pseudocontinuous term for each nutrient in these models, and assessed the significance of this term using the Wald test.

Cox regression models were fitted, with age as the time axis[30], to estimate hazard ratios (HRs) and 95\% confidence intervals, separately for each nutrient measure and for alcohol consumption. To test for heterogeneity in the HRs by attained age at follow-up ( $\leq 55$ years vs. $>55$ years, where 55 years was the age at which $95 \%$ of women in our sample had reached the menopause) we split the attained age during follow-up into the two specified age groups and fitted Cox models with an interaction term between each nutrient and the age groups. To test for heterogeneity in the HRs by hormone receptor status (ER+/PR+ vs. ER-\&PR-), we fitted Cox regression models for competing risk using a data duplication method[31].

All analyses were adjusted for ethnicity (Australian/New Zealand, United Kingdom, Greek, Italian); menopausal status (pre, post); age at menarche $(<12 \mathrm{y}, 12 \mathrm{y}, 13 \mathrm{y}, 14 \mathrm{y}+)$; parity and lactation (nulliparous, parous and never lactated, parous and lactated); OC use (never, ever); HRT use (never, ex-user, current user); physical activity score $(0,>0$ to $<4,4$ to $<6, \geq 6$ ); alcohol consumption (lifetime abstainer, low $1-19 \mathrm{~g} / \mathrm{d}$, moderate $20-39 \mathrm{~g} / \mathrm{d}$, high intake $\geq 40 \mathrm{~g} / \mathrm{d}$ ); smoking status (never, current, former); education (primary school, some high school, completed high school, completed degree/diploma) and BMI. Models for alcohol consumption were also adjusted for daily energy from food. Interactions between hormone receptor subtype and each confounder were included in our competing risk models. 
To examine the interaction of each B vitamin with methionine and the interaction of each nutrient with folate, nutrient intakes were dichotomized at the medians. Separate Cox regression models were fitted for ER+/PR+ and ER-\&PR- breast cancer. Due to few women in the high alcohol consumption category, each nutrient was treated as a continuous variable and the four alcohol consumption categories were retained in our models, to investigate the interaction of each nutrient with alcohol.

We conducted sensitivity analyses by repeating our analyses including only women of Australian, New Zealand or United Kingdom descent; using ER and PR measures obtained from immunohistochemistry only or the VCR only; excluding women who reported consuming multivitamins at baseline; excluding women with cancer at any site prior to baseline and excluding the first 2 years of follow-up to eliminate the possibility that the observed relationships were influenced by pre-existing disease. Mandatory folate-fortification of bread flour was introduced in Australia during 2009 [32]. To determine whether folate fortification influenced our findings, we repeated our analyses using the end of follow-up as 31 December 2008, to investigate associations in the pre-fortification period.

Statistical analyses were performed using Stata/SE 12.1 (Stata Corporation, College Station, TX). P $<0.05$ (twosided) was considered statistically significant. Tests based on Schoenfeld residuals showed no evidence of violation of the proportional hazards assumption

\section{Results}

Of the eligible women, $143(0.2 \%)$ left Australia and 1898 (9.1\%) died by 30 June 2010, and $77(0.4 \%)$ left Victoria between 1 January 2005 and 30 June 2010. The mean age at diagnosis was 64 years (range 41-86 years). Baseline characteristics and mean daily energy-adjusted nutrient intakes for the study sample are shown in Table 1.

Spearman correlation coefficients between energy-adjusted intakes of riboflavin and folate $(\rho=0.37)$, vitamin B12 and vitamin B6 $(\rho=0.50)$ and vitamin B12 and methionine $(\rho=0.56)$ were moderate, but weak between the other B vitamins and methionine (all $\rho<0.17$; data not shown). 
Table 2 shows the HRs for overall breast cancer risk and by hormone receptor status in relation to B vitamin and methionine intakes. For overall breast cancer, we observed a weak inverse association with riboflavin intake $\left(\mathrm{HR}_{\mathrm{Q} 4 \text { vs. Q1 }}=0.84(0.69,1.01) ; \mathrm{P}_{\text {linear trend }}=0.05\right)$ and a weak positive association with vitamin $\mathrm{B} 12$ intake $\left(\mathrm{HR}_{\mathrm{Q} 4}\right.$ vs. $\left.\mathrm{Q} 1=1.21(1.00,1.46) ; \mathrm{P}_{\text {linear trend }}=0.06\right)$. For folate intake, we observed a reduced risk for $\mathrm{Q} 2$ vs. Q1 of $0.80(0.66$, 0.96), but no associations for the other quartiles. The inclusion of a quadratic term suggested a J-shaped relationship between vitamin $\mathrm{B} 6$ and breast cancer risk $(\mathrm{P}=0.008)$ with a minimum $\mathrm{HR}$ at $\mathrm{Q} 2$ vs. Q1 of 0.81 $(0.67,0.97)$, but there was no evidence of a departure from linearity in the relationships for any other B vitamin or methionine (all $\mathrm{P}>0.05$ ). None of the observed associations varied significantly by attained age at follow-up ( $\leq 55$ years vs. $>55$ years, all $\left.\mathrm{P}_{\text {homogeneity }}>0.32\right)$ or by hormonal receptor status $(\mathrm{ER}+\mathrm{PR}+\mathrm{vs.} \mathrm{ER- \& PR-, \text {all }}$ $\left.\mathrm{P}_{\text {homogeneity }}>0.14\right)$. For vitamin B6 intake we observed a weak positive association for ER+/PR+ breast cancer $\left(\mathrm{HR}_{\mathrm{Q} 4 \text { vs. Q1 }}=1.12(0.91,1.38) ; \mathrm{P}_{\text {linear trend }}=0.06\right)$, but a U-shaped association for ER-\&PR- $\left(\mathrm{P}_{\text {quadratic term }}=0.02\right)$. We did not observe any other associations or departures from linearity (all P>0.19) for ER+/PR+ or ER-\&PR- breast cancer.

Alcohol consumption was not linearly associated with overall breast cancer, ER+/PR+ or ER-\&PR- subtype, although a non-significant elevated HR for Q4 vs. Q1 of $1.15(0.78,1.69)$ for overall breast cancer and 1.36 $(0.89,2.07)$ for $\mathrm{ER}+\mathrm{PR}+$ subtype was observed for women consuming $\geq 40 \mathrm{~g} / \mathrm{d}$ alcohol (Table 3$)$. There was no significant heterogeneity by hormonal receptor status for alcohol (ER+/PR+ vs. ER-\&PR-, $\left.\mathrm{P}_{\text {homogeneity }}=0.20\right)$.

We did not observe any statistically significant interactions between alcohol consumption and intake of B vitamins or methionine for overall breast cancer risk (all $\mathrm{P}_{\text {interaction }}>0.17$ ). We did not have enough cases in the high alcohol consumption group to assess alcohol-nutrient interactions by hormonal receptor status.

We did not observe any significant interactions between methionine or folate and the other B vitamins for overall breast cancer, but there was a borderline significant interaction between folate and methionine $(\mathrm{P}=0.07)$ : a reduced risk for women with high folate/high methionine intake compared with high folate/low methionine, $\mathrm{HR}=0.81(0.68,0.96)$ and an increased risk for women with low methionine/high folate compared with low methionine/low folate, $\mathrm{HR}=1.22(1.02,1.45)$ (Table 4). A similar pattern was observed for ER+/PR+ subtype $\left(\mathrm{P}_{\text {interaction }}=0.04\right)$ but no other associations were observed for ER-\&PR- subtype or overall breast cancer. 
Additional analyses excluding the first 2 years of follow-up; including only women of Australian, New Zealand or United Kingdom descent; using ER and PR measures obtained from immunohistochemistry only or the VCR only; excluding women who reported consuming multivitamins at baseline; excluding women with pre-baseline cancer at any site; and including only the pre-folate fortification period (follow-up to the end of 2008) did not materially change the HR estimates.

\section{Discussion}

Overall, we found suggestive evidence of a weak inverse association between riboflavin intake and breast cancer risk, and a weak positive association for vitamin B12 intake. We found no linear associations with alcohol consumption, although there was weak evidence that higher intakes were associated with higher risk, particularly for ER+/PR+ subtype. We did not observe any significant interactions between alcohol consumption, folate, methionine and any of the other nutrients for overall breast cancer risk. Nonetheless, there was some evidence to suggest that higher methionine intakes might protect against breast cancer (particularly $\mathrm{ER}+/ \mathrm{PR}+$ subtype) in women with high folate intakes.

Our study strengths include virtually complete follow-up as the identification of incident breast cancer cases was performed by record linkage to the Australian population-based cancer registries that have complete coverage of the cohort participants. Although the interstate linkage is complete only up to the end of 2004, only 3 cases were diagnosed interstate between 1990 and 2004; thus it is unlikely that we have missed many interstate cases. Only $0.2 \%$ of women left Australia during follow-up so we would not expect to have missed many cases diagnosed overseas. Analyses excluding the first 2 years of follow-up gave similar associations to those reported, thus it is unlikely that our findings were influenced by pre-existing disease. Further analyses restricted to women of Australian, New Zealand or United Kingdom descent or women who did not report any pre-baseline cancer at any site did not substantially affect our findings, nor did restricting our hormone receptor status analyses to using measures obtained from immunohistochemistry reports only or the VCR only.

Our study's limitations include the fact that information on diet and potential confounding variables was only collected at baseline and might not be relevant to the full time period. We could not account for any change in 
dietary habits over follow-up, although older people tend to have stable diets[33]. Further, inter-correlations between B vitamins and methionine[34] make it difficult to estimate the effect of a single nutrient. Our FFQ has not been validated specifically for B vitamins, only for fatty acids [26] and carotenoids [27]. However, a similar FFQ which was derived from the one used in the current study, has been previously validated for some B vitamins [35]. For some subgroups, particularly for interaction analyses and in our highest alcohol consumption category, the small number of cases led to low precision. Given the number of comparisons performed, some associations might be due to chance alone. Voluntary folic acid fortification of foods has been progressively introduced in Australia and fortification of bread flour has been mandatory since 2009[32] Although we were unable to account for this, there were no substantial differences in associations when we restricted our analyses to the pre-fortification period (using the end of follow-up as the end of 2008). Some misclassification of nutrient intake is inevitable since we only assessed dietary intake and did not have data on supplemental B vitamin intake. However, only $19 \%$ of women in our sample used multivitamins, so it is unlikely that this lack of information would have substantially affected our estimates. Furthermore, analyses restricted to women who did not consume multivitamins at baseline showed similar associations to those for all women in our study. Intakes of $\mathrm{B}$ vitamins are estimated from FFQs with considerable error; a fact supported by the weak correlations between dietary and serum levels of B vitamins[6,36], although metabolic effects may also contribute to variations in circulating levels. Misclassification of dietary intakes will attenuate any estimate of association between diet and cancer and could, thus, contribute to differences in the results between studies using dietary intakes or biomarkers.

Generally, no linear associations have been reported for dietary intakes of riboflavin $[15,9,10]$, although a weak inverse association was reported by the Long Island Breast Cancer Study Project, a population-based casecontrol study, but only among non-supplemental users [14]. Consistent with our findings, non-significant reduced risks were reported for higher intakes of riboflavin in some studies[14,9,10]. We did not observe any associations by hormone receptor subtype, consistent with others[8,10].

Some studies have reported no linear associations for dietary intakes of B6 for overall breast cancer risk[4,5,811,6] or by ER or PR subtype[4,8,10], consistent with our findings. A suggestive J-shaped association with overall breast cancer was reported from a case-control study nested within the Women's Health Study for total B6 intake, but not for B6 from food only [6] and a Japanese hospital-based case-control study reported a 
possible U-shaped association with B6 intake [8]. These studies are consistent with the suggestive J-shaped relationship we observed for total breast cancer risk and the U-shaped relationship for ER-\&PR- subtype for dietary B6 intake.

Most studies reported no association for vitamin B12 intake, for overall breast cancer risk[4,7-11,13] or by hormonal receptor subtype[4,8,10]. The weak positive association we observed for vitamin B12 intake for total breast cancer was consistent with findings from a case-control study nested within the Women's Health Study for total B12 intake [6]. They reported a HR of $1.44[1.02,2.04]$ for the highest versus lowest quintile, but no association was observed for B12 intake from food only [6].

Evidence from experimental studies suggests that folate deficiency might promote initial stages of carcinogenesis, whereas excess folic acid might stimulate existing neoplasms[37-39], however, we did not find an overall association between breast cancer risk and folate intake. Two recent meta-analyses reported no association between breast cancer risk and folate intake in prospective studies, consistent with our findings, but reported an inverse association in case-control studies[2,3]. However, Larsson et al [2] identified heterogeneity between studies of each type of study design, and Lewis et al [3] noted that the association between breast cancer risk and folate intake observed in the case-control studies might be due to a combination of chance, bias, measurement error and/or confounding. We did not find any associations for ER+/PR+ or ER-\&PR- subtypes consistent with others[18,8]. Inconsistent associations have been reported by others for ER and PR status and various combinations of these receptors $[19,6,9,17,10]$.

Several studies reported no associations for methionine intake and overall breast cancer risk $[4,15,10,13]$, or by hormone receptor status[10], consistent with our findings, but in contrast to an inverse association reported by the Cancer Prevention Study II Nutrition Cohort[11].

Epidemiological studies have consistently reported a modest positive association between alcohol consumption and breast cancer risk, particularly for hormone-receptor positive tumours[20], which is consistent with the weak elevated risks we observed in our study for overall breast cancer and ER+/PR+ tumours for heavier drinkers. Alcohol is a known folate-antagonist that can impair folate absorption and metabolism [21]. Although, there is evidence that the association between breast cancer risk and alcohol consumption might be 
modified by intakes of folate[20], including in an earlier study using MCCS data with a shorter follow-up period (and restricted to Anglo-Australian women)[40], we did not find a significant interaction between alcohol and folate, consistent with others[4,15,41,18,9,11,42,43]. Two studies reported a stronger protective effect for ERwith higher intakes of folate for higher alcohol consumers[44,17]. We did not have enough cases to investigate folate-alcohol interactions by hormonal receptor status. Consistent with others we found no significant interactions between alcohol and riboflavin[15,8], vitamin B6[4,8,11], vitamin $\mathrm{B} 12[8,4,11]$ or methionine[4,15,11].

In one folate-metabolism pathway, the enzyme, 5,10-methylenetetrahydrofolate reductase (MTHFR) catalyses the irreversible conversion of 5,10-methylenetetrahydrofolate to 5-methyltetrahydrofolate, the primary circulating form of folate which is used for the remethylation of homocysteine to methionine. MTHFR redirects the pool of folate from DNA synthesis/repair to methylation. Thus MTHFR activity and availability of folate might affect DNA methylation and DNA synthesis and there is some evidence that MTHFR genotypes might modify the association between dietary intake of B vitamins and breast cancer risk [45-47]. We observed an increased risk of breast cancer associated with high folate intakes for women with low methionine intakes, which is in contrast to what we might expect, however other factors such as MTHFR affect circulating folate and methionine and we were unable account for these. Others have generally reported no strong evidence of a folate-methionine interaction and breast cancer[4,15,9-11]. Consistent with others we found no strong evidence that folate modified the associations between breast cancer risk and riboflavin[9,15,41,10], vitamin $\mathrm{B} 6[4,9-11]$ or vitamin B12[4,9-11].

Our findings suggest a weak inverse association between breast cancer risk and riboflavin intake and a weak positive association for vitamin B12. We found some evidence that high methionine intake might be protective of breast cancer in women with high folate intakes.

\section{Acknowledgements}

This study was made possible by the contribution of many people, including the original investigators and the diligent team who recruited the participants and who continue working on follow-up. We would also like to express our gratitude to the many thousands of Melbourne residents who continue to participate in the study. We would like to acknowledge the work of David Muller who checked all statistical analyses. Cohort recruitment 
was funded by VicHealth and The Cancer Council Victoria. This work was supported by infrastructure from the Cancer Council Victoria and grants from the NHMRC (209057, 251533, 520316).

\section{Conflict of interest}

The authors declare no conflict of interest. 


\section{References}

1. Kim YI (2004) Folate and DNA methylation: a mechanistic link between folate deficiency and colorectal cancer? Cancer Epidemiol Biomarkers Prev 13:511-519

2. Larsson SC, Giovannucci E, Wolk A (2007) Folate and risk of breast cancer: a meta-analysis. J Natl Cancer Inst 99:64-76. doi:10.1093/jnci/djk006

3. Lewis SJ, Harbord RM, Harris R, Smith GD (2006) Meta-analyses of observational and genetic association studies of folate intakes or levels and breast cancer risk. J Natl Cancer Inst 98:1607-1622.

doi:10.1093/jnci/djj440

4. Cho E, Holmes M, Hankinson SE, Willett WC (2007) Nutrients involved in one-carbon metabolism and risk of breast cancer among premenopausal women. Cancer Epidemiol Biomarkers Prev 16:2787-2790. doi:10.1158/1055-9965.epi-07-0683

5. Lajous M, Lazcano-Ponce E, Hernandez-Avila M, Willett W, Romieu I (2006) Folate, vitamin B(6), and vitamin B(12) intake and the risk of breast cancer among Mexican women. Cancer Epidemiol Biomarkers Prev 15:443-448. doi:10.1158/1055-9965.epi-05-0532

6. Lin J, Lee IM, Cook NR, Selhub J, Manson JE, Buring JE et al. (2008) Plasma folate, vitamin B-6, vitamin B12, and risk of breast cancer in women. Am J Clin Nutr 87:734-743

7. Ma E, Iwasaki M, Junko I, Hamada GS, Nishimoto IN, Carvalho SM et al. (2009) Dietary intake of folate, vitamin B6, and vitamin B12, genetic polymorphism of related enzymes, and risk of breast cancer: a casecontrol study in Brazilian women. BMC Cancer 9:122. doi:10.1186/1471-2407-9-122

8. Ma E, Iwasaki M, Kobayashi M, Kasuga Y, Yokoyama S, Onuma H et al. (2009) Dietary intake of folate, vitamin B2, vitamin B6, vitamin B12, genetic polymorphism of related enzymes, and risk of breast cancer: a case-control study in Japan. Nutr Cancer 61:447-456. doi:10.1080/01635580802610123

9. Maruti SS, Ulrich CM, White E (2009) Folate and one-carbon metabolism nutrients from supplements and diet in relation to breast cancer risk. Am J Clin Nutr 89:624-633. doi:10.3945/ajcn.2008.26568 10. Shrubsole MJ, Shu XO, Li HL, Cai H, Yang G, Gao YT et al. (2011) Dietary B vitamin and methionine intakes and breast cancer risk among Chinese women. Am J Epidemiol 173:1171-1182. doi:10.1093/aje/kwq491 11. Stevens VL, McCullough ML, Sun J, Gapstur SM (2010) Folate and other one-carbon metabolism-related nutrients and risk of postmenopausal breast cancer in the Cancer Prevention Study II Nutrition Cohort. Am J Clin Nutr 91:1708-1715. doi:10.3945/ajcn.2009.28553 
12. Wu K, Helzlsouer KJ, Comstock GW, Hoffman SC, Nadeau MR, Selhub J (1999) A prospective study on folate, B12, and pyridoxal 5'-phosphate (B6) and breast cancer. Cancer Epidemiol Biomarkers Prev 8:209-217 13. Zhang CX, Ho SC, Chen YM, Lin FY, Fu JH, Cheng SZ (2011) Dietary folate, vitamin B6, vitamin B12 and methionine intake and the risk of breast cancer by oestrogen and progesterone receptor status. Br J Nutr 106:936-943. doi:10.1017/s0007114511001140

14. Chen J, Gammon MD, Chan W, Palomeque C, Wetmur JG, Kabat GC et al. (2005) One-carbon metabolism, MTHFR polymorphisms, and risk of breast cancer. Cancer Res 65:1606-1614. doi:10.1158/0008-5472.can-042630

15. Kabat GC, Miller AB, Jain M, Rohan TE (2008) Dietary intake of selected B vitamins in relation to risk of major cancers in women. Br J Cancer 99:816-821. doi:10.1038/sj.bjc.6604540

16. Zhu K, Williams SM (1998) Methyl-deficient diets, methylated ER genes and breast cancer: an hypothesized association. Cancer Causes Control 9:615-620

17. Zhang SM, Hankinson SE, Hunter DJ, Giovannucci EL, Colditz GA, Willett WC (2005) Folate intake and risk of breast cancer characterized by hormone receptor status. Cancer Epidemiol Biomarkers Prev 14:20042008. doi:10.1158/1055-9965.epi-05-0083

18. Larsson SC, Bergkvist L, Wolk A (2008) Folate intake and risk of breast cancer by estrogen and progesterone receptor status in a Swedish cohort. Cancer Epidemiol Biomarkers Prev 17:3444-3449. doi:10.1158/1055-9965.epi-08-0692

19. Ericson U, Borgquist S, Ivarsson MI, Sonestedt E, Gullberg B, Carlson J et al. (2010) Plasma folate concentrations are positively associated with risk of estrogen receptor beta negative breast cancer in a Swedish nested case control study. J Nutr 140:1661-1668. doi:10.3945/jn.110.124313

20. Coronado GD, Beasley J, Livaudais J (2011) Alcohol consumption and the risk of breast cancer. Salud Publica Mex 53:440-447

21. Halsted CH, Villanueva JA, Devlin AM, Chandler CJ (2002) Metabolic interactions of alcohol and folate. J Nutr 132:2367S-2372S

22. Giles GG, English DR (2002) The Melbourne Collaborative Cohort Study. IARC Sci Publ 156:69-70 23. Baglietto L, Severi G, English DR, Krishnan K, Hopper JL, McLean C et al. (2010) Circulating steroid hormone levels and risk of breast cancer for postmenopausal women. Cancer Epidemiol Biomarkers Prev 19:492-502. doi:10.1158/1055-9965.epi-09-0532 
24. Ireland P, Jolley D, Giles G, O’Dea K, Powles J, Rutishauser I et al. (1994) Development of the Melbourne FFQ: a food frequency questionnaire for use in an Australian prospective study involving an ethnically diverse cohort. Asia Pac J Clin Nutr 3:19-31

25. FSANZ (2006) Food Standards Australia New Zealand. NUTTAB 2006.

http://www.foodstandards.gov.au/consumerinformation/nuttab2006/onlineversionintroduction/onlineversion.cf m. Accessed July 2010 .

26. Hodge AM, Simpson JA, Gibson RA, Sinclair AJ, Makrides M, O'Dea K et al. (2007) Plasma phospholipid fatty acid composition as a biomarker of habitual dietary fat intake in an ethnically diverse cohort. Nutr Metab Cardiovasc Dis 17:415-426. doi:10.1016/j.numecd.2006.04.005

27. Hodge AM, Simpson JA, Fridman M, Rowley K, English DR, Giles GG et al. (2009) Evaluation of an FFQ for assessment of antioxidant intake using plasma biomarkers in an ethnically diverse population. Public Health Nutr 12:2438-2447. doi:10.1017/s1368980009005539

28. MacInnis RJ, English DR, Hopper JL, Haydon AM, Gertig DM, Giles GG (2004) Body size and composition and colon cancer risk in men. Cancer Epidemiol Biomarkers Prev 13:553-559

29. Willett W, Stampfer MJ (1986) Total energy intake: implications for epidemiologic analyses. Am J Epidemiol 124:17-27

30. Korn EL, Graubard BI, Midthune D (1997) Time-to-event analysis of longitudinal follow-up of a survey: choice of the time-scale. Am J Epidemiol 145:72-80

31. Lunn M, McNeil D (1995) Applying Cox regression to competing risks. Biometrics 51:524-532

32. FSANZ (2009) Food Standards Australian New Zealand 2.1.1 Clause 4.

http://wwwcomlawgovau/Details/F2009C00811. Accessed April 2012

33. Jungjohann SM, Luhrmann PM, Bender R, Blettner M, Neuhauser-Berthold M (2005) Eight-year trends in food, energy and macronutrient intake in a sample of elderly German subjects. Br J Nutr 93:361-378.

doi:S0007114505000462 [pii]

34. Key T (1994) Micronutrients and cancer aetiology: the epidemiological evidence. Proc Nutr Soc 53:605614. doi:S002966519400073X [pii]

35. Hodge A, Patterson AJ, Brown WJ, Ireland P, Giles G (2000) The Anti Cancer Council of Victoria FFQ: relative validity of nutrient intakes compared with weighed food records in young to middle-aged women in a study of iron supplementation. Aust N Z J Public Health 24:576-583 
36. Zhang SM, Willett WC, Selhub J, Hunter DJ, Giovannucci EL, Holmes MD et al. (2003) Plasma folate, vitamin B6, vitamin B12, homocysteine, and risk of breast cancer. J Natl Cancer Inst 95:373-380

37. Ebbing M, Bonaa KH, Nygard O, Arnesen E, Ueland PM, Nordrehaug JE et al. (2009) Cancer incidence and mortality after treatment with folic acid and vitamin B12. JAMA 302:2119-2126. doi:302/19/2119 [pii] 10.1001/jama.2009.1622 [doi]

38. Kim YI (2007) Folate and colorectal cancer: an evidence-based critical review. Mol Nutr Food Res 51:267292. doi:10.1002/mnfr.200600191 [doi]

39. Ulrich CM, Potter JD (2007) Folate and cancer--timing is everything. JAMA 297:2408-2409. doi:297/21/2408 [pii] 10.1001/jama.297.21.2408 [doi]

40. Baglietto L, English DR, Gertig DM, Hopper JL, Giles GG (2005) Does dietary folate intake modify effect of alcohol consumption on breast cancer risk? Prospective cohort study. BMJ 331:807. doi:10.1136/bmj.38551.446470.06

41. Lajous M, Romieu I, Sabia S, Boutron-Ruault MC, Clavel-Chapelon F (2006) Folate, vitamin B12 and postmenopausal breast cancer in a prospective study of French women. Cancer Causes Control 17:1209-1213. doi:10.1007/s10552-006-0053-3

42. Duffy CM, Assaf A, Cyr M, Burkholder G, Coccio E, Rohan T et al. (2009) Alcohol and folate intake and breast cancer risk in the WHI Observational Study. Breast Cancer Res Treat 116:551-562. doi:10.1007/s10549008-0167-2

43. Tjonneland A, Christensen J, Olsen A, Stripp C, Thomsen BL, Overvad K et al. (2007) Alcohol intake and breast cancer risk: the European Prospective Investigation into Cancer and Nutrition (EPIC). Cancer Causes Control 18:361-373. doi:10.1007/s10552-006-0112-9

44. Sellers TA, Vierkant RA, Cerhan JR, Gapstur SM, Vachon CM, Olson JE et al. (2002) Interaction of dietary folate intake, alcohol, and risk of hormone receptor-defined breast cancer in a prospective study of postmenopausal women. Cancer Epidemiol Biomarkers Prev 11:1104-1107

45. Maruti SS, Ulrich CM, Jupe ER, White E (2009) MTHFR C677T and postmenopausal breast cancer risk by intakes of one-carbon metabolism nutrients: a nested case-control study. Breast Cancer Res 11:R91. doi:10.1186/bcr2462 
46. Shrubsole MJ, Gao YT, Cai Q, Shu XO, Dai Q, Hebert JR et al. (2004) MTHFR polymorphisms, dietary folate intake, and breast cancer risk: results from the Shanghai Breast Cancer Study. Cancer Epidemiol Biomarkers Prev 13:190-196

47. Zintzaras E (2006) Methylenetetrahydrofolate reductase gene and susceptibility to breast cancer: a metaanalysis. Clin Genet 69:327-336. doi:10.1111/j.1399-0004.2006.00605.x 
Table 1. Baseline characteristics of participants

\begin{tabular}{|c|c|c|c|c|}
\hline & \multicolumn{2}{|c|}{ All } & \multicolumn{2}{|c|}{ Cases } \\
\hline $\mathrm{N}$ & 20756 & & 936 & \\
\hline Age at baseline, mean ( $S D)$ & 55 & (9) & 56 & (8) \\
\hline BMI $\left(\mathrm{kg} / \mathrm{m}^{2}\right)$, mean $(S D)$ & 26.5 & (4.8) & 26.8 & (4.8) \\
\hline Energy $(\mathrm{kJ} / \mathrm{d})$, mean $(S D)$ & 8578 & (2828) & 8664 & $(2828)$ \\
\hline $\operatorname{Riboflavin}^{\mathrm{a}}(\mathrm{mg} / \mathrm{d})$, mean $(S D)$ & 2.4 & $(0.8)$ & 2.4 & $(0.7)$ \\
\hline Vitamin $\mathrm{B}^{\mathrm{a}}(\mathrm{mg} / \mathrm{d})$, mean $(S D)$ & 2.1 & (1.5) & 2.1 & (1.7) \\
\hline Vitamin $\mathrm{B} 12^{\mathrm{a}}(\mu \mathrm{g} / \mathrm{d})$, mean $(S D)$ & 3.1 & (1.9) & 3.2 & $(2.2)$ \\
\hline Folate $^{\mathrm{a}}(\mu \mathrm{g} / \mathrm{d})$, mean $(S D)$ & 322 & (92) & 323 & $(88)$ \\
\hline Methionine $^{\mathrm{a}}(\mathrm{mg} / \mathrm{d})$, mean $(S D)$ & 1554 & (397) & 1535 & (391) \\
\hline \multicolumn{5}{|l|}{ Ethnicity, $n(\%)$} \\
\hline Australian/New Zealand & 14989 & (72) & 744 & (79) \\
\hline United Kingdom & 1379 & (7) & 50 & (5) \\
\hline Italian & 2405 & (12) & 88 & (9) \\
\hline Greek & 1983 & (10) & 54 & (6) \\
\hline \multicolumn{5}{|l|}{ Age at menarche, $n(\%)$} \\
\hline$<12 \mathrm{y}$ & 3364 & (16) & 158 & (17) \\
\hline $12 \mathrm{y}$ & 4066 & (20) & 175 & (19) \\
\hline $13 \mathrm{y}$ & 5486 & (26) & 243 & (26) \\
\hline$\geq 14 \mathrm{y}$ & 7840 & (38) & 360 & (38) \\
\hline \multicolumn{5}{|l|}{ Parity \& lactation, $n(\%)$} \\
\hline Nulliparous & 2993 & (14) & 166 & (18) \\
\hline Parous, never lactated & 1233 & (6) & 58 & (6) \\
\hline Parous, lactated & 16530 & (80) & 712 & (76) \\
\hline \multicolumn{5}{|l|}{ OC use, $n(\%)$} \\
\hline Never user & 8269 & (40) & 374 & (40) \\
\hline Ever user & 12487 & (60) & 562 & (60) \\
\hline \multicolumn{5}{|l|}{ HRT use, $n(\%)$} \\
\hline Never user & 15384 & (74) & 639 & (68) \\
\hline Ex-user & 1760 & (8) & 73 & (8) \\
\hline Current user & 3612 & (17) & 224 & (24) \\
\hline \multicolumn{5}{|l|}{ Menopausal status, $n(\%)$} \\
\hline premenopausal & 7617 & (37) & 339 & (36) \\
\hline postmenopausal & 13139 & (63) & 597 & (64) \\
\hline \multicolumn{5}{|l|}{ Physical activity score, $n(\%)$} \\
\hline 0 & 4465 & (22) & 174 & (19) \\
\hline$>0$ and $<4$ & 4423 & (21) & 208 & (22) \\
\hline$\geq 4$ and $<6$ & 7517 & (36) & 351 & (38) \\
\hline$\geq 6$ & 4351 & (21) & 203 & (22) \\
\hline \multicolumn{5}{|l|}{ Alcohol consumption, $n(\%)$} \\
\hline Abstainers & 8035 & (39) & 357 & (38) \\
\hline Low intake $(1-19 g / d)$ & 10262 & (49) & 465 & (50) \\
\hline Medium intake $(20-39 \mathrm{~g} / \mathrm{d})$ & 1905 & (9) & 84 & (9) \\
\hline High intake $(\geq 40 \mathrm{~g} / \mathrm{d})$ & 554 & (3) & 30 & (3) \\
\hline \multicolumn{5}{|l|}{ Smoking, $n(\%)$} \\
\hline Never & 14461 & (70) & 669 & (71) \\
\hline Current & 1814 & (9) & 64 & (7) \\
\hline Former & 4481 & (22) & 203 & (22) \\
\hline \multicolumn{5}{|l|}{ Education, $n(\%)$} \\
\hline$\leq$ Primary school & 3842 & (19) & 127 & (14) \\
\hline Some high/technical school & 8959 & (43) & 425 & (45) \\
\hline Completed high/technical school & 3725 & (18) & 175 & (19) \\
\hline Degree/diploma & 4230 & (20) & 209 & (22) \\
\hline
\end{tabular}

${ }^{a}$ Adjusted for energy

NOTE: percentages may not add up to $100 \%$ due to rounding 
Table 2. Hazard ratios ${ }^{\mathrm{a}}$ (HRs) and $95 \%$ confidence intervals $(95 \%$ CIs) for breast cancer risk in relation to dietary intake of B vitamins and methionine

\begin{tabular}{|c|c|c|c|c|c|c|c|c|c|c|}
\hline \multirow[b]{2}{*}{ Quartile (median) } & \multicolumn{3}{|c|}{ All breast cancer } & \multicolumn{3}{|c|}{ ER+/PR+ } & \multicolumn{3}{|c|}{ ER-\&PR- } & \multirow[b]{2}{*}{ P-value ${ }^{c}$} \\
\hline & Cases & HR & $(95 \% \mathrm{CI})$ & Cases & HR & $(95 \% \mathrm{CI})$ & Cases & HR & $(95 \% \mathrm{CI})$ & \\
\hline \multicolumn{11}{|l|}{ Riboflavin (mg/d) } \\
\hline Q1 (1.68) & 233 & 1.00 & & 162 & 1.00 & & 48 & 1.00 & & \\
\hline Q2 (2.14) & 243 & 0.98 & $(0.81,1.17)$ & 191 & 1.09 & $(0.89,1.35)$ & 42 & 0.81 & $(0.53,1.23)$ & \\
\hline Q3 (2.55) & 237 & 0.93 & $(0.77,1.12)$ & 172 & 0.96 & $(0.77,1.19)$ & 48 & 0.89 & $(0.59,1.34)$ & \\
\hline Q4 (3.19) & 223 & 0.84 & $(0.69,1.01)$ & 165 & 0.88 & $(0.70,1.10)$ & 41 & 0.72 & $(0.47,1.11)$ & \\
\hline Linear model $^{\mathrm{b}}$ & 936 & 0.93 & $(0.87,1.00)$ & 690 & 0.94 & $(0.87,1.01)$ & 179 & 0.90 & $(0.78,1.05)$ & 0.65 \\
\hline P-value for linear trend & & 0.05 & & & 0.11 & & & 0.19 & & \\
\hline \multicolumn{11}{|l|}{ Vitamin B6 (mg/d) } \\
\hline Q1 (1.25) & 251 & 1.00 & & 173 & 1.00 & & 56 & 1.00 & & \\
\hline Q2 (1.56) & 206 & 0.81 & $(0.67,0.97)$ & 148 & 0.83 & $(0.67,1.04)$ & 43 & 0.75 & $(0.50,1.11)$ & \\
\hline Q3 (1.88) & 220 & 0.84 & $(0.70,1.01)$ & 173 & 0.95 & $(0.77,1.17)$ & 35 & 0.60 & $(0.39,0.91)$ & \\
\hline Q4 (2.80) & 259 & 1.03 & $(0.86,1.22)$ & 196 & 1.12 & $(0.91,1.38)$ & 45 & 0.80 & $(0.54,1.18)$ & \\
\hline Linear model $^{\mathrm{b}}$ & 936 & 1.04 & $(0.97,1.11)$ & 690 & 1.07 & $(1.00,1.16)$ & 179 & 0.94 & $(0.80,1.10)$ & 0.14 \\
\hline P-value for linear trend & & 0.24 & & & 0.06 & & & 0.45 & & \\
\hline \multicolumn{11}{|l|}{ Vitamin B12 $(\mu \mathrm{g} / \mathrm{d})$} \\
\hline Q1 (1.66) & 234 & 1.00 & & 174 & 1.00 & & 48 & 1.00 & & \\
\hline Q2 (2.33) & 244 & 1.06 & $(0.89,1.27)$ & 186 & 1.09 & $(0.89,1.35)$ & 43 & 0.89 & $(0.59,1.34)$ & \\
\hline Q3 (3.04) & 209 & 0.94 & $(0.78,1.14)$ & 154 & 0.95 & $(0.77,1.19)$ & 39 & 0.82 & $(0.53,1.27)$ & \\
\hline Q4 (4.61) & 249 & 1.21 & $(1.00,1.46)$ & 176 & 1.19 & $(0.95,1.47)$ & 49 & 1.09 & $(0.71,1.68)$ & \\
\hline Linear model $^{\mathrm{b}}$ & 936 & 1.07 & $(1.00,1.14)$ & 690 & 1.05 & $(0.97,1.14)$ & 179 & 1.05 & $(0.89,1.23)$ & 0.93 \\
\hline P-value for linear trend & & 0.06 & & & 0.19 & & & 0.59 & & \\
\hline \multicolumn{11}{|l|}{ Folate $(\mu \mathrm{g} / \mathrm{d})$} \\
\hline Q1 (224) & 238 & 1.00 & & 166 & 1.00 & & 48 & 1.00 & & \\
\hline Q2 (286) & 198 & 0.80 & $(0.66,0.96)$ & 143 & 0.82 & $(0.66,1.03)$ & 43 & 0.84 & $(0.56,1.27)$ & \\
\hline Q3 (340) & 241 & 0.93 & $(0.78,1.12)$ & 187 & 1.03 & $(0.83,1.27)$ & 41 & 0.78 & $(0.50,1.19)$ & \\
\hline Q4 (422) & 259 & 0.99 & $(0.83,1.19)$ & 194 & 1.05 & $(0.85,1.29)$ & 47 & 0.89 & $(0.59,1.34)$ & \\
\hline Linear model $^{\mathrm{b}}$ & 936 & 1.02 & $(0.95,1.09)$ & 690 & 1.04 & $(0.96,1.13)$ & 179 & 0.96 & $(0.82,1.12)$ & 0.35 \\
\hline $\mathrm{P}$-value for linear trend & & 0.60 & & & 0.30 & & & 0.60 & & \\
\hline \multicolumn{11}{|l|}{ Methionine (mg/d) } \\
\hline Q1 (1154) & 242 & 1.00 & & 180 & 1.00 & & 43 & 1.00 & & \\
\hline Q2 (1398) & 255 & 1.04 & $(0.88,1.25)$ & 175 & 0.96 & $(0.78,1.19)$ & 57 & 1.28 & $(0.86,1.91)$ & \\
\hline Q3 (1616) & 219 & 0.90 & $(0.75,1.08)$ & 179 & 0.99 & $(0.80,1.22)$ & 29 & 0.65 & $(0.40,1.05)$ & \\
\hline Q4 (1969) & 220 & 0.97 & $(0.80,1.17)$ & 156 & 0.94 & $(0.75,1.18)$ & 50 & 1.17 & $(0.76,1.81)$ & \\
\hline Linear model ${ }^{\mathrm{b}}$ & 936 & 0.98 & $(0.91,1.04)$ & 690 & 0.98 & $(0.91,1.06)$ & 179 & 1.00 & $(0.85,1.18)$ & 0.84 \\
\hline $\mathrm{P}$-value for linear trend & & 0.47 & & & 0.66 & & & 0.99 & & \\
\hline
\end{tabular}

${ }^{a}$ Adjusted for ethnicity, menopausal status, age at menarche, parity and lactation, oral contraceptive use, hormone replacement therapy use, physical activity, alcohol consumption, smoking status, education level, and BMI

${ }^{\mathrm{b}}$ HRs per $1 \mathrm{SD}$ increment

${ }^{\mathrm{c}}$ Test for homogeneity in the HRs for linear trend (or quadratic trend for vitamin B6) between women with ER+/PR+ vs. ER-\&PR- breast cancer 
Table 3. Hazard ratios ${ }^{a}$ (HRs) and $95 \%$ confidence intervals $(95 \%$ CIs) for breast cancer risk in relation alcohol consumption

\begin{tabular}{|c|c|c|c|c|c|c|c|c|c|c|}
\hline & \multicolumn{3}{|c|}{ All breast cancer } & \multicolumn{3}{|c|}{ ER+/PR+ } & \multicolumn{3}{|c|}{ ER-\&PR- } & \multirow[b]{2}{*}{ P-value } \\
\hline & Cases & HR & $(95 \% \mathrm{CI})$ & Cases & HR & $(95 \% \mathrm{CI})$ & Cases & HR & $(95 \% \mathrm{CI})$ & \\
\hline \multicolumn{11}{|l|}{ Alcohol consumption: } \\
\hline Abstainers & 357 & 1.00 & & 254 & 1.00 & & 68 & 1.00 & & \\
\hline Low intake $(1-19 g / d)$ & 465 & 0.97 & $(0.84,1.12)$ & 345 & 1.02 & $(0.86,1.21)$ & 93 & 0.98 & $(0.71,1.35)$ & \\
\hline Medium intake $(20-39 \mathrm{~g} / \mathrm{d})$ & 84 & 0.94 & $(0.73,1.21)$ & 66 & 1.05 & $(0.79,1.41)$ & 15 & 0.87 & $(0.48,1.58)$ & \\
\hline High intake $(\geq 40 \mathrm{~g} / \mathrm{d})$ & 30 & 1.15 & $(0.78,1.69)$ & 25 & 1.36 & $(0.89,2.07)$ & 3 & 0.61 & $(0.19,1.93)$ & \\
\hline Linear model (per $10 \mathrm{~g} / \mathrm{d}$ ) & 936 & 1.01 & $(0.95,1.07)$ & 690 & 1.04 & $(0.97,1.12)$ & 179 & 0.93 & $(0.80,1.09)$ & \\
\hline $\mathrm{P}$-value for linear trend & & 0.80 & & & 0.25 & & & 0.37 & & 0.20 \\
\hline
\end{tabular}

P-value for linear trend

Adjusted for ethnicity, menopausal status, age at menarche,

${ }^{\mathrm{b}}$ Test for homogeneity in the HRs for linear trend between women with ER+/PR+ vs. ER-\&PR- breast cancer 
Table 4. Hazard ratios ${ }^{\mathrm{a}}$ (HRs) and $95 \%$ confidence intervals (95\% CIs) for breast cancer risk in relation to dietary intake of folate and methionine

\begin{tabular}{|c|c|c|c|c|c|}
\hline & \multicolumn{5}{|c|}{ High $^{\mathrm{b}}$ versus low $^{\mathrm{b}}$ folate intake ${ }^{\mathrm{c}}$} \\
\hline & All breast cancer & \multicolumn{2}{|c|}{$\mathbf{E R + / P R +}$} & \multicolumn{2}{|r|}{ ER-\&PR- } \\
\hline & HR $\quad(95 \% \mathrm{CI})$ & HR & $(95 \% \mathrm{CI})$ & HR & $(95 \% \mathrm{CI})$ \\
\hline Low methionine intake ( $\leq$ median) & $1.22 \quad(1.02,1.45)$ & 1.33 & $(1.08,1.65)$ & 1.02 & $(0.69,1.52)$ \\
\hline High methionine intake (>median) & $0.96 \quad(0.79,1.16)$ & 0.97 & $(0.78,1.21)$ & 0.82 & $(0.52,1.29)$ \\
\hline \multirow[t]{4}{*}{ P-interaction } & 0.07 & 0.04 & & 0.47 & \\
\hline & \multicolumn{5}{|c|}{ High $^{b}$ versus low $^{b}$ methionine intake ${ }^{c}$} \\
\hline & All breast cancer & \multicolumn{2}{|c|}{ ER+/PR+ } & \multicolumn{2}{|r|}{ ER-\&PR- } \\
\hline & HR $\quad(95 \% \mathrm{CI})$ & HR & $(95 \% \mathrm{CI})$ & HR & $(95 \% \mathrm{CI})$ \\
\hline Low folate intake ( $\leq$ median $)$ & $1.03 \quad(0.85,1.24)$ & 1.16 & $(0.92,1.46)$ & 0.88 & $(0.57,1.34)$ \\
\hline High folate intake (>median) & $0.81 \quad(0.68,0.96)$ & 0.84 & $(0.69,1.03)$ & 0.70 & $(0.46,1.08)$ \\
\hline P-interaction & 0.07 & 0.04 & & 0.47 & \\
\hline
\end{tabular}

${ }^{a}$ Adjusted for ethnicity, menopausal status, age at menarche, parity and lactation, oral contraceptive use, hormone replacement therapy use, physical activity, alcohol consumption, smoking status, education level, and BMI. Separate models for ER+/PR+ and ER-\&ER-

${ }^{\mathrm{b}}$ High intake > median; Low intake $\leq$ median

${ }^{\mathrm{c}}$ HRs are derived from the same model 